\title{
Sleep Disorders in Menopause: Review of the Literature and Occurrence through Menopausal Stages
}

\author{
Maria Elena Pessa ${ }^{1,2 *}$, Francesco Janes ${ }^{1}$, Gian Luigi Gigli1,3, Mariarosaria Valente ${ }^{1,2}$ \\ ${ }^{1}$ Neurology Clinic Department of Neurological Sciences, Santa Maria della Misericordia University Hospital, Udine, Italy \\ ${ }^{2}$ Department of Medical Area, University of Udine, Udine, Italy \\ ${ }^{3}$ Department of Mathematical, Computer and Physical Sciences, University of Udine, Udine, Italy \\ Email: *marialen@gmail. $\infty \mathrm{m}$
}

How to cite this paper: Pessa, M.E., Janes, F., Gigli, G.L. and Valente, M. (2019) Sleep Disorders in Menopause: Review of the Literature and Occurrence through Menopausal Stages. Health, 11, 472-488. https://doi.org/10.4236/health.2019.115041

Received: March 12, 2019

Accepted: May 13, 2019

Published: May 16, 2019

\section{Copyright (c) 2019 by author(s) and} Scientific Research Publishing Inc. This work is licensed under the Creative Commons Attribution International License (CC BY 4.0).

http://creativecommons.org/licenses/by/4.0/

\section{(c) (i) Open Access}

\begin{abstract}
We here review principal literature data about sleep disorders in menopause and we compared it with data obtained from a systematical screening of a sample of 161 menopausal women through questionnaires and clinical evaluation. Our data reveal high occurrence of sleep disorders in this group of women if compared to literature data about general population, in the absence of statistically significant differences among the three menopausal stages: we find only a trend toward a higher risk of OSAS (Obstructive Sleep Apnea Syndrome) in PM versus early PM and MT. However, none of women in our survey underwent PSG (polysomnography), essential to confirm the diagnosis of OSAS and none was diagnosed with RLS (Restless Legs Syndrome) (prior to our survey) by the Gynecologist or General Pratictioner: these data reveal the issue of too low attention towards sleep disorders in this contest. Generic "sleep complaints" are clearly associated with depressed mood and worse-quality life along the menopausal process. In our sample, a non-specific definition of insomnia shows a peculiar relationship with a mood disorder: it is only variable not associated with higher BDI and KI scores, in fact. This might suggest that the conditions linked to depression of these women could be more specific sleep disturbances, such as RLS and OSAS.
\end{abstract}

\section{Keywords}

Menopause, Sleep Disorders, Menopausal Stages, Restless Legs Syndrome,

Obstructive Sleep Apnea Syndrome

\section{Introduction}

Accumulating evidence suggests that quantity and quality of sleep is an impor- 
tant factor associated with health and mortality. Short sleep is associated with insulin resistance, glucose homeostasis, endothelial function, activation of the sympathetic nervous system and inflammatory pathways, supporting the notion that sleep is not a sole function of the brain but has a wider influence on body functions, including metabolism and cardiovascular function. Some studies also found that long sleep duration was associated with a greater risk of cardiovascular diseases (CVD) [1]. It is not clear, however, if longer sleep determines CVD, or instead if it is the underlying disease to induce subjects to sleep more.

It is well known that sleep deteriorates with age: a meta-analysis of 65 studies [2] showed a decline in total sleep time, sleep efficiency, slow wave sleep (SWS) and REM sleep from young adulthood to elderly subjects.

Menopause results from reduced secretion of estrogen and progesterone, which takes place as the finite store of ovarian follicles is depleted. Using the STRAW (Stages of Reproductive Aging Workshop, 2011) criteria, menopause is defined as the period of a woman's life after 12 months of amenorrhea. The stage immediately before is the Menopausal Transition (MT), denoted by alterations of cycle lengths. The period after the final menstrual period is termed early post-menopause and is estimated to be approximately 5 years in duration. The Latter stage is defined simply as post-menopause (PM) [3].

Sleep disturbances are more common among women than men at any stage of their life [4], but more women report poor sleep as they age, increasing from approximately $12 \%$ in younger women to approximately $40 \%$ in women in their late 40s and early 50s [5]. Prevalence of sleep disorders is also reported to increase dramatically during menopausal transition: according to data reported in NIH State of the Science Conference on management of menopause-related symptoms (2005), they affect $16 \%-42 \%$ of pre-menopausal women, $39 \%-47 \%$ of women in MT and 35\% - 60\% of women in early PM and PM. Most cross-cultural studies in the last decade provided support for sleep quality deterioration during the MT compared to post-menopause [6] [7] [8].

Evidence of changes in sleep patterns in menopause derives from a few small polysomnographic (PSG) studies and is discordant. In some no difference in any PSG sleep pattern has been observed, despite women in menopause subjectively reported bad sleep [9] [10]. Others revealed in PM and almost in MT less total sleep time, deep sleep and more WASO than in young women [11] [12].

The challenge is to discriminate how this increased poor sleep complaint is actually related to menopausal transition and not only a consequence of ageing.

\subsection{Insomnia}

It is defined as a difficulty in falling asleep, in maintaining sleep, or the feeling that sleep is non-restorative, with daytime consequences (Darien I.L. American Academy of Sleep Medicine. The International Classification of Sleep Disorders 3rd Edition, 2014).

Accumulating evidence suggests that depressive and vasomotor symptoms are the most important risk factor for insomnia and impaired sleep quality in me- 
nopause and MT [13] [14].

\section{- Vasomotor Symptoms (VMS)}

They manifest as hot flushes (sensation of heat), hot flashes (episodes with sweating) and night sweats. The mechanism causing those is not fully understood. One theory is that reduced estrogen causes decreased endorphin concentrations in the hypothalamus, which increases the release of norepinephrine and serotonin, which lowers the set point in the thermoregulatory nucleus and trigger inappropriate heat loss [15] [16]: this hypothesis is supported by the reduction of VMS by serotonin-norepinephrine reuptake inhibitors (SNRI), which rebalance serotonin and norepinephrine systems.

The percentage of women reporting VMS [17] [18] is high, between 50\% and $75 \%$ [19] [20]. They are typical for MT and frequently resolve within a few months, but in some cases can persist for several years (up to $29 \%$ of 60 -year-old women reported persistent hot flashes) [21]. There is numerous evidence of correlation among insomnia, poor sleep and VMS. A study in which estrogen deficiency was induced with a GnRH agonist in healthy premenopausal women demonstrates that hot flashes are associated with: 1) an increase in episodes of WASO 2) a decrease in perceived sleep efficiency, and 3) a statistically significant correlation between nocturnal VMS and sleep disruption [22]. Actigraphy sleep studies detect more and longer WASO [23] [24]. In PSG studies nocturnal hot flashes are found almost only during the first 4 hours of sleep [25] and are associated with more N1, less N3 sleep and reduced sleep efficiency [26].

Some observations on VMS being related to increased actigraphy-detected wakefulness, but not to alterations of total sleep time or latency [23] suggested that a compensation (longer time in bed) for increased WASO was retained, thus preserving total sleep time. An important factor could be the time when VMA events occur: in fact, since the first half of the night is the period when the relative proportion of deep sleep is greater, when individuals are deprived of deep sleep in the first half of the night, compensation occurs through more deep sleep in the second half of the night, making total sleep time unchanged [27].

Prevalence of VMS and insomnia through reproductive and menopause phases varies: fewer women in late reproductive age (12.5\% and 36.5\%) and PM stage (39.3\% and 50.7\%) report respectively VMS and chronic insomnia; however, the ratio was reversed in the MT stage (79.0\% VMS and 56.6\% chronic insomnia) [28]. This implies that 1) some women might have had insomnia before entering the MT, 2) VMS might be present before menstrual bleeding irregularity is noticed and/or 3) sleep, especially in PM, is impacted by factors other than VMS (so general ageing sleep changes become a predominant factor).

\section{- Anxiety and Depressed Mood}

During their lifetime, women are more vulnerable than men to developing depressed mood and a subset of them seems to be particularly sensitive to hypothalamic-pituitary-ovarian hormone variations [29]. Numerous studies have shown that, during the MT, the prevalence of depression rises apparently inde- 
pendently of other known factors [29] [30] [31] [32]. The literature evidence of the link of depressive symptoms with sleep problems is consistent [33] [34] and the association has also been documented in peri-menopausal and postmenopausal women [15]. The Depressed mood has been observed in people with primary sleep disorders and insomnia is a frequent complaint in depressed patients. Some have postulated that MT-related VMS provoke sleep disturbance that induces mood disorders, but many others have evidenced that in women with depressed mood there is an amplification of multiple MT symptoms, particularly bad sleep quality and VMS (that are reported more frequent and of higher intensity) [35]. Women exhibiting MT-related depressed mood did not differ by the presence or absence of VMS. Additionally, actigraphy sleep studies reveal that there is no difference (between depressed and not) in the number of VMS correlated with awakenings and women with perceived poor sleep show longer sleep latency and shortened sleep time but do not show more or longer WASO (that are typical in VMS-related sleep alteration) [36]. PSG studies in depressed/anxious patients are frequently characterized by REM sleep fragmentation and in a small study of menopausal women increased the percentage of REM sleep has a positive relationship with depression score [37].

\subsection{Restless Legs Syndrome (RLS)}

RLS is a disorder characterized by disagreeable sensations in the legs (itching, creeping, tingling, usually between the ankle and the knee) that provoke an irresistible urge to move and are relieved temporarily with movements. Patients typically complain of these sensations in the evening, during the night or when they are at rest. In Caucasian population, it has a prevalence of about 5\%-15\%. One large study reported an overall prevalence of $7 \%$, but clinically significant in about $2.7 \%$ [38]. Periodic limb movement of sleep (PLMS) is a stereotyped leg movement (extension of the big toe with partial flexion of the ankle, knee and sometimes the hip) that, in addition to be present as an independent sleep disorder, may develop in about $80 \%-90 \%$ of patients with RLS.

There are a primary and a secondary forms of RLS. The Primary form has earlier onset (less than 45 years old), higher incidence in women, increasing severity with age and a strong familiar link. Among secondary forms, iron deficiency and end-stage renal disease represent major causes of RLS, but it may also occur in association with pregnancy, diabetes, polyneuropathy and multiple sclerosis [39] [40] [41].

Some studies correlate RLS and PLMS with increased cardio-cerebrovascular events, possibly as a consequence of sympathetic over activity and chronic intermittent hypoxia. However, recent reviews reveal inconsistent and limited available evidence on this association and highlight the vast presence of confounding factors [42] [43].

Its pathophysiological bases are not completely clear, but evidence suggests involvement of dopamine and iron systems. In particular, its dramatic response 
to dopaminergic medications suggests a brain dopamine deficiency. However, recent studies suggest a hyper-dopaminergic state in these patients (it has been found an increase in both 3-orthymethyl dopamine and the dopamine metabolite homovanillic acid in the CSF) [44] [45]: it has been postulated that in RLS there could be a circadian profile of dopamine activity that reflects hyper-functioning in the morning and throughout the day, followed by relative hypo-functioning in the evening and nighttime.

Although the serum iron is often normal, people with RLS have a state of low iron in the brain. This has been demonstrated in neuropathological specimens, brain imaging and cerebrospinal fluid (CSF) evaluation. The brain areas most consistently showing iron reduction include the substantia nigra and, to a lesser extent, the putamen and caudate nucleus. Dysregulation of iron transport across blood-brain barrier is one possible mechanism [46].

A role of reproductive hormones in RLS is suggested by the prevalence in women and by the association or worsening in periods of increased endogenous estradiol levels [47] [48]: based on these data one could expect a drop in RLS prevalence after menopause as a consequence of drop of estrogens levels. There are few studies evaluating this sleep disorder in menopause, but all revealed increased severity of a pre-existent RLS (in until 69\% of patients) [49] [50]. On the other side, numerous epidemiological data show an increase of prevalence and severity in both genders [51], which could suggest that a confounding factor in the assessment of RLS prevalence in menopause might be represented by increasing age and related co-morbidity.

\subsection{Obstructive Sleep Apnea Syndrome (OSAS)}

OSAS is a syndrome characterized by apneas or hypopneas during sleep. It results in intermittent arousals, hypoxemia and increased sympathetic activity. Affected patients complain of Insomnia, daytime sleepiness, memory impairment, decreased quality of life and are at greater risk for coronary artery disease, hypertension and stroke [52].

Pathogenesis is related to an excessive collapse of airways during inspiration, caused by craniofacial malformations and/or deposition of adipose tissue at the level of neck and tongue and/or reduction of functional residual capacity caused by increased abdominal circumference.

Prevalence is higher in men and it has been increasing over the last decades: now it is estimated around 13\% in men and 6\% in women [51]. Among females, OSAS affects especially early PM and PM women and it's reported in about $20 \%$ [53] [54].

Well-known risk factors during menopause are of course increased body weight and redistribution of fat, with increased waist and neck circumference. However, menopausal status remains a significant risk factor for OSAS even after adjusting for body mass index, waist circumference or waist to hip ratio: despite a comparable BMI, post-menopausal women have more severe sleep apnea syndrome when compared to pre-menopausal ones [55]. This could be the con- 
sequence of caused by female hormones drop by two mechanisms: increased upper airway collapse and also reduced central respiratory drive. A recent study using drug-induced sleep endoscopy shows a tendency to more severe airway obstruction in all parts of the airways in menopausal women than in men with similar age and BMI [56]: evidences in rats suggest that it could be done to decrease genioglossus tone, that inversely correlate with estradiol concentration [57]. It has also been observed that postmenopausal women possess a reduced central chemoreflex drive to breathe that is associated with decreased circulating female sex steroid hormone concentrations [58]. Some epidemiological studies in large population-based cohorts found that combined treatment with progesterone and estrogens was associated with reduced prevalence of sleep-disordered breathing [59] [60].

\subsection{The Role of Hormonal Therapy}

There are several different mechanisms by which menopause-related changes in estrogen and progesterone levels (and consequent HT) could influence sleep. Estrogen has a thermoregulatory effect and is involved in norepinephrine, serotonin and acetylcholine metabolism, all neurotransmitters involved in sleep regulation. It increases REM cycles and total sleep time, decreases sleep latency, number of awakenings during the night and seems to have a role in decreasing the number of cyclic spontaneous arousals [61].

Progesterone stimulates benzodiazepine receptors and has sedative and anxiolytic properties [62]. A high clinical dose of micronized progesterone given orally 1.5 hours before bedtime significantly shorted the latency to REM sleep and increased the amount of non-REM sleep in a small group of young men [63].

Generally, HT administered to women in the MT is observed to improve sleep; however, the effects seem to be modest and co-occur with improvement in the other symptoms, in particular VMS [64] [65]. In one actigraphy sleep study (in 3000 menopausal women), those on hormone therapy were less likely to wake up after falling asleep and experienced fewer and shorter wake episodes [66]. Also, most PSG studies reveal shorten sleep latency, less WASO, increased REM sleep, but whether this occurs by direct effect of ovarian hormones or by indirect effect (via alleviation of other sleep-interfering symptoms) is difficult to answer.

\subsection{Occurrence and Impact of Specific Sleep Disorders in Menopausal Women}

Among all the several previous studies that analyze sleep disturbances during the menopausal process very few of them describe in detail the role of specific sleep disorders diagnosis. This is reasonably due to the practical difficulties in following and studying women all along the menopausal transition period, which means for several years, as well as to the need for objective and instrumental evaluations, which require resources that are often expensive and unavailable 
even in dedicated sleep services. We here tried, through questionnaires and clinical evaluation, to create an overview, a screening approach, that could give an idea of specific disorders' role in menopausal sleep disturbances. Given the intrinsic limitation of this method, our reasonable goal is only to clarify if sleep complains in menopausal women show a consistent trend independently from the definite diagnosis, or if a specific profile could identify women at higher risk, the possible target of a personalized instrumental investigation and therapeutic strategy.

\section{Methods}

We enrolled consecutive women $>18$ years old attending the Menopause Surgery of the Clinic of Gynecology and Obstetrics of Udine's "Aziendaospedaliero-Universitaria S. Mariadella Misericordia" between February and September 2017. All these patients were then evaluated in our Sleep Clinic by a Neurologist expert in Sleep Disorders.

We collected data about socio-demographical characteristics, age of the last menstrual cycle, lifestyle (BMI, smoking, consumption of alcohol, coffee), medical history and pharmacotherapy. We administered the Berlin Questionnaire for OSAS's risk [67], the International Restless Legs Syndrome Study Group Rating Scale (IRLSSGRS) [68] for RLS evaluation; the Beck Depression Inventory (BDI) to quantify mood disorder [69]; the Epworth Sleepiness Scale (ESS) [70] and the Pittsburgh Sleep Quality Index (PSQI) [71] were used to asses sleep quality; the Kupperman Index (KI) was used as an already validated tool to assess quality of life in menopausal women [72].

Through these tools we identified four different patterns of sleep disorders:

- RLS: disagreeable sensations in the legs that provoke an irresistible urge to move and are relieved temporarily with movements;

- high/low risk of OSAS, defined by more or less than 2 points in Berlin Questionnaire;

- insomnia: difficulty in falling asleep, in maintaining sleep, or the feeling that sleep is non-restorative, with daytime consequences (Darien I.L. American Academy of Sleep Medicine. The International Classification of Sleep Disorders 3rd edition, 2014);

- isolated insomnia: insomnia in patients who don't present any other sleep disorder.

The menopausal process is classified into 3 stages according to STRAW criteria $[3]$ :

- menopausal transition (MT);

- early postmenopause (ePM);

- post menopause (PM).

\section{Statistical Analysis}

Continuous variables are described by mean \pm standard deviation (sd) and categorical variables are described with number out of total. Differences among the 
groups were explored by ANOVA analysis and a p-value $<0.05$ was considered statistically significant. Statistical analysis was carried out using the SPSS13 software.

\section{Results}

The examined sample consists of 161 women, whose Mean age is $55 \pm 6.7$ years and the mean age of menopause is $49 \pm 4.9,19 \%$ of women are in MT, $43 \%$ in early PM and $38 \%$ in PM.

Insomnia is reported by $43 \%$ of the total population, almost initial.

Physical, socio-demographical characteristics, habits and comorbidities among all patients are shown in Table 1.

Hypertension and smoke habit are more common in PM women than MT, but the three groups do not differ in other baseline characteristics.

We do not find a statistical difference in the occurrence of sleep disorders across the three stages, as shown in Table 2.

RLS appears higher than in general population, $21.7 \%$ in the total studied population.

However, it has to be noted that this data could overestimate the real prevalence of RLS in menopause: our sample consists of women attending a gynecologic service, likely suffering of some menopausal-related disturbances.

This higher occurrence of RLS could suggest and be explained as a consequence of fluctuating hormonal levels in MT and of the additional effect of ageing in PM women.

Table 1. Clinical characteristics of 161 menopausal women, according to menopausal stage.

\begin{tabular}{|c|c|c|c|c|}
\hline & $\begin{array}{c}\text { M.T. } \\
\text { 30/161 (19\%) } \\
\text { n(\%) or } \\
\text { mean } \pm \text { sd }\end{array}$ & $\begin{array}{c}\text { eP.M. } \\
\text { 69/161 (43\%) } \\
\text { n }(\%) \text { or } \\
\text { mean } \pm \text { sd }\end{array}$ & $\begin{array}{c}\text { P.M. } \\
\text { 62/161 (38\%) } \\
\mathrm{n}(\%) \text { or } \\
\text { mean } \pm \mathrm{sd}\end{array}$ & $\begin{array}{c}\text { p-value } \\
\left(\chi^{2} \text { or Fisher's }\right. \\
\text { exact test })\end{array}$ \\
\hline Age & $50.3 \pm 3.5$ & $52.9 \pm 5.3$ & $59.6 \pm 6.6$ & $<0.001$ \\
\hline B.M.I. & $24.4 \pm 3.3$ & $25.8 \pm 4.9$ & $25.1 \pm 3.6$ & 0.305 \\
\hline Waist & $82.7 \pm 9.6$ & $86.3 \pm 12.1$ & $84.4 \pm 10.9$ & 0.345 \\
\hline Neck circumference & $33.3 \pm 3.3$ & $33.9 \pm 3.0$ & $33.9 \pm 2.9$ & 0.592 \\
\hline Hypertension & $5.0 \%$ & $47.5 \%$ & $47.5 \%$ & 0.035 \\
\hline $\begin{array}{c}\text { Smoke } \\
\text { (smoker/previous smoker) }\end{array}$ & $8(11.8 \%)$ & $37(54.4 \%)$ & $23(33.8 \%)$ & 0.026 \\
\hline Regular alcohol consumption & $0(0 \%)$ & $1(0.01 \%)$ & $1(0.01 \%)$ & 0.719 \\
\hline Benzodiazepine use & $10(33.3 \%)$ & $15(21.7 \%)$ & $15(24.2 \%)$ & 0.47 \\
\hline Antidepressants & $1(3.3 \%)$ & $6(8.7 \%)$ & $6(9.7 \%)$ & 0.56 \\
\hline Diabetes & $1(3.3 \%)$ & $1(1.4 \%)$ & $1(1.6 \%)$ & 0.80 \\
\hline Renal Failure & $0(0)$ & $1(1.4 \%)$ & $0(0)$ & 0.51 \\
\hline Anemia & $1(3.3 \%)$ & $2(2.9 \%)$ & $3(4.8 \%)$ & 0.84 \\
\hline Thyroid dysfunction & $5(16.7 \%)$ & $12(17.4 \%)$ & $12(19.4 \%)$ & 0.94 \\
\hline
\end{tabular}

MT, Menopausal Transition; ePM, early Post Menopause; PM, Post Menopause; BMI, Body Mass Index. 
Table 2. Specific sleep disturbance occurrence according to menopausal stage.

\begin{tabular}{|c|c|c|c|c|}
\hline & $\begin{array}{c}\text { MT } \\
30 / 161(19 \%) \\
\text { (n) } \%\end{array}$ & $\begin{array}{c}\text { ePM } \\
69 / 161(43 \%) \\
\text { (n) } \% \\
\end{array}$ & $\begin{array}{c}\text { PM } \\
62 / 161(38 \%) \\
\text { (n) } \% \\
\end{array}$ & $\begin{array}{c}\text { p-value } \\
\left(\chi^{2} \text { or Fisher's }\right. \\
\text { exact test })\end{array}$ \\
\hline RLS & (7) $23.3 \%$ & (12) $17.4 \%$ & (16) $25.8 \%$ & 0.49 \\
\hline High risk OSAS & (3) $10.0 \%$ & (16) $23.5 \%$ & (16) $25.8 \%$ & 0.21 \\
\hline Isolated insomnia & (8) $26.7 \%$ & (15) $21.7 \%$ & (13) $21.0 \%$ & 0.82 \\
\hline All Insomnias & (13) $43.3 \%$ & (28) $40.6 \%$ & (28) $42.9 \%$ & 0.87 \\
\hline Any Sleep Complain & $18(60.0 \%)$ & $41(59.4 \%)$ & $41(66.1)$ & 0.70 \\
\hline
\end{tabular}

MT, Menopausal Transition; ePM, early Post Menopause; PM, Post Menopause; RLS, Rest Less Syndrome; OSAS, Obstructive Sleep Apnea Syndrome.

We note a trend toward a higher risk of OSAS in PM compared to MT. Waist, neck circumference, Mallampati score and hypertension are significantly higher or more frequent in high-risk-OSAS women (Table 3).

As expected, sleep disorders as a whole (see "Any Sleep Complain") show to affect both a quality of life index (KI) and a mood disorders one (BDI): this is still true in isolated RLS and OSAS subjects, who present a higher BDI and KI scores, but peculiarly it is not confirmed for insomnia as an isolated self-reported symptom (Table 4).

However, quality of life and depression estimating indexes (BDI, KI) are not different throughout menopausal stages (Table 5).

\section{Discussion}

Several studies evaluate generically sleep disorders, with different methodologies, at different time-points, often as a global construct. To the best of our knowledge, only one of them (69) evaluates systematically specific sleep disorders in menopausal women. According to literature data, the principal complaint of menopausal women seemed to be insomnia related to vasomotor symptoms during MT, but few studies measured objective indices of sleep quality and they revealed mild sleep architecture changes. The most frequently observed physical sleep pattern changes are PSG total sleep time, WASO, and, in some cases, sleep efficiency. Among possible sleep stage changes, less N1 and REM sleep have been observed, the latter mostly evident in patients with depressed mood.

We show in our study data which corroborate the suggestion of a higher occurrence of sleep disorders in this group of women if compared to the general population. However, there seems to be no statistically significant differences among the three menopausal stages.

We noted only a trend toward a higher risk of OSAS in PM versus early PM and MT.

High occurrence of OSAS in PM is thought to be a consequence of physical modifications and higher prevalence of hypertension secondary to ageing and hormonal changes. Here we confirm this hypothesis: in our sample waist, neck circumference, Mallampati score and hypertension are significantly higher or 
Table 3. Physical characteristics, comorbidities, smoke and drug use in patients with and without sleep disorders.

\begin{tabular}{|c|c|c|c|c|c|c|c|c|c|}
\hline & Waist & Mallampati & $\begin{array}{c}\text { Neck } \\
\text { Circumf. }\end{array}$ & BMI & HTN & Smoke & $\begin{array}{c}\text { Thyroid } \\
\text { dysfunction }\end{array}$ & $\mathrm{BDZ}$ & Antidepressants \\
\hline RLS & $84.7 \pm 12.5$ & $1.43 \pm 0.61$ & $34.2 \pm 3.5$ & $25.2 \pm 4.5$ & $6(17.1 \%)$ & $16(45.7 \%)$ & $8(22.9 \%)$ & $13(37.1)$ & $5(14.3 \%)$ \\
\hline No RLS & $85.1 \pm 10.9$ & $1.46 \pm 0.61$ & $33.7 \pm 2.9$ & $25.3 \pm 4.1$ & $34(27.0 \%)$ & $52(41.3 \%)$ & $21(16.7 \%)$ & $27(21.4)$ & $8(6.3 \%)$ \\
\hline $\begin{array}{c}\text { P-value } \\
\left(T-T e s t, \chi^{2} \text { or }\right. \\
\text { Fisher's exact test })\end{array}$ & 0.84 & 0.79 & 0.39 & 0.89 & 0.23 & 0.64 & 0.40 & 0.06 & 0.13 \\
\hline High-Risk OSAS & $92.7 \pm 12.3$ & $1.77 \pm 0.69$ & $35.5 \pm 3.5$ & $28.9 \pm 5.0$ & $26(74.3)$ & $17(48.6)$ & $12(34.3)$ & $11(31.4)$ & $3(8.6)$ \\
\hline Low-Risk OSAS & $82.9 \pm 9.9$ & $1.37 \pm 0.56$ & $33.3 \pm 2.7$ & $24.2 \pm 3.3$ & $14(11.1)$ & $51(40.5)$ & $17(13.5)$ & $29(23.0)$ & $10(7.9)$ \\
\hline $\begin{array}{c}\text { P-value } \\
\left(T-\text {-Test, } \chi^{2} \text { or }\right. \\
\text { Fisher's exact test })\end{array}$ & $<0.001$ & $<0.001$ & $<0.001$ & $<0.001$ & $<0.001$ & 0.39 & 0.005 & 0.31 & 0.90 \\
\hline All Insomnias & $84.0 \pm 9.1$ & $1.49 \pm 0.61$ & $33.7 \pm 2.8$ & $25.4 \pm 3.4$ & $18(26.1 \%)$ & $35(50.7 \%)$ & $15(21.7 \%)$ & $28(40.6 \%)$ & $5(7.2 \%)$ \\
\hline No Insomnia & $85.8 \pm 12.6$ & $1.42 \pm 0.61$ & $33.9 \pm 3.2$ & $25.2 \pm 4.7$ & $22(23.9 \%)$ & $33(35.9 \%)$ & $14(15.2 \%)$ & $12(13.0 \%)$ & $8(8.7 \%)$ \\
\hline $\begin{array}{c}P \text {-value } \\
\left(T-\text { Test, } \chi^{2} \text { or }\right. \\
\text { Fisher's exact test })\end{array}$ & 0.28 & 0.48 & 0.75 & 0.74 & 0.75 & 0.06 & 0.29 & $<0.001$ & 0.74 \\
\hline Isolated Insomnia & $82.0 \pm 9.1$ & $1.44 \pm 0.56$ & $33.1 \pm 2.7$ & $24.9 \pm 3.7$ & $5(13.9 \%)$ & $15(41.7 \%)$ & $7(19.4 \%)$ & $15(41.7 \%)$ & $1(2.8 \%)$ \\
\hline $\begin{array}{l}\text { No Isolated } \\
\text { Insomnia }\end{array}$ & $85.9 \pm 11.7$ & $1.46 \pm 0.63$ & $34.0 \pm 3.1$ & $25.3 \pm 4.3$ & $35(28 \%)$ & $53(42.4 \%)$ & $22(17.6 \%)$ & $25(20.0 \%)$ & $12(9.6 \%)$ \\
\hline $\begin{array}{c}P \text {-value } \\
\left(T-\text {-Test, } \chi^{2} \text { or }\right. \\
\text { Fisher's exact test })\end{array}$ & 0.07 & 0.92 & 0.11 & 0.60 & 0.06 & 0.94 & 0.80 & 0.008 & 0.16 \\
\hline Any Sleep Compl. & $85.8 \pm 11.4$ & $1.52 \pm 0.63$ & $34.1 \pm 3.2$ & $26.0 \pm 4.5$ & $33(33.0 \%)$ & $45(45.0 \%)$ & $24(24.0 \%)$ & $35(35.0 \%)$ & $9(9.0 \%)$ \\
\hline No Sleep Compl. & $83.7 \pm 10.9$ & $1.34 \pm 0.57$ & $33.3 \pm 2.7$ & $24.0 \pm 3.2$ & $7(11.5 \%)$ & $23(37.7 \%)$ & $5(8.2 \%)$ & $5(8.2 \%)$ & $4(6.6 \%)$ \\
\hline $\begin{array}{c}P \text {-value } \\
\left(T-\text {-Test }, \chi^{2} \text { or }\right. \\
\left.\text { Fisher }{ }^{2} \text { exact test }\right)\end{array}$ & 0.25 & 0.07 & 0.08 & 0.003 & 0.002 & 0.36 & 0.01 & $<0.001$ & 0.58 \\
\hline
\end{tabular}

more frequent in high-risk-OSAS women (Table 3). However, none of the women in our survey underwent PSG, essential to confirm the diagnosis. Consequently, these data should be considered carefully. This also reveals the issue of too low attention towards sleep disorders in this contest by general and gynecologist practitioners. This underestimation of specific sleep disorders is confirmed by our high detection (21.7\%) of RLS, that has not been previously diagnosed and so none of these women was assuming dopaminergic therapy (the gold standard treatment for RLS).

As shown in Table 3, a non-specific definition of insomnia in our sample shows a peculiar relationship with a mood disorder: it is the only variable not associated with higher BDI and KI scores, in fact. This might suggest that even if "generic sleep complains" are clearly associated with depressed mood and a worse life quality along the menopausal process, the actual conditions linked to depression in these women could be more specific sleep disturbances, such as RLS and OSAS. 
Table 4. Scores of KI (Kupperman Index) and BDI (Beck Depression Inventory) of patients with and without sleep disorders.

\begin{tabular}{|c|c|c|}
\hline & B.D.I. & K.I. \\
\hline RLS & $13.6 \pm 9.6$ & $16.2 \pm 11.9$ \\
\hline No RLS & $10.3 \pm 5.7$ & $12.3 \pm 9.1$ \\
\hline$P$-value $\left(\chi^{2}\right.$ or Fisher's exact test $)$ & 0.06 & 0.04 \\
\hline High Risk OSAS & $13.2 \pm 8.1$ & $17.0 \pm 10.0$ \\
\hline Low Risk OSAS & $10.4 \pm 6.3$ & $12.1 \pm 9.5$ \\
\hline$P$-value $\left(\chi^{2}\right.$ or Fisher's exact test $)$ & 0.07 & 0.01 \\
\hline All Insomnias & $12.0 \pm 7.3$ & $16.2 \pm 10.4$ \\
\hline No insomnia & $10.2 \pm 6.4$ & $10.9 \pm 8.8$ \\
\hline$P$-value $\left(\chi^{2}\right.$ or Fisher's exact test $)$ & 0.10 & 0.001 \\
\hline Isolated insomnia & $9.7 \pm 4.3$ & $13.9 \pm 8.3$ \\
\hline No Isolated insomnia & $11.4 \pm 7.3$ & $12.9 \pm 10.2$ \\
\hline$P$-value ( $\chi^{2}$ or Fisher's exact test) & 0.08 & 0.61 \\
\hline Any Sleep Complain & $12.1 \pm 7.5$ & $15.2 \pm 10.0$ \\
\hline No Sleep Complain & $9.3 \pm 5.1$ & $9.7 \pm 8.5$ \\
\hline$P$-value $\left(\chi^{2}\right.$ or Fisher's exact test $)$ & 0.006 & 0.001 \\
\hline
\end{tabular}

BDI, Beck Depression Inventory; KI, Kupperman Index; RLS, Rest Less Syndrome; OSAS, Obstructive Sleep Apnea Syndrome.

Table 5. Estimation of sleep somnolence, sleep quality, quality of life and depression throughout menopausal stages.

\begin{tabular}{ccccc}
\hline & $\begin{array}{c}\text { M.T. } \\
\text { (mean } \pm \text { sd) or } \\
\text { frequency }(\%)\end{array}$ & $\begin{array}{c}\text { eP.M. } \\
\text { (mean } \pm \text { sd) or } \\
\text { frequency }(\%)\end{array}$ & $\begin{array}{c}\text { P.M. } \\
\text { (mean } \pm \text { sd) or } \\
\text { frequency }(\%)\end{array}$ & $\begin{array}{c}\text { p-value } \\
\left(\chi^{2} \text { or Fisher's }\right. \\
\text { exact test })\end{array}$ \\
\hline ESS score & $5.5 \pm 3.3$ & $5.1 \pm 4.3$ & $5.0 \pm 3.5$ & 0.86 \\
Daily sleepiness & $12.5 \%$ & $12.2 \%$ & $9.4 \%$ & 0.92 \\
PSQI score & $5.3 \pm 1.9$ & $5.3 \pm 2.6$ & $5.6 \pm 2.6$ & 0.69 \\
Poor sleep & $56.7 \%$ & $54.4 \%$ & $62.9 \%$ & 0.61 \\
B.D.I. & $12.4 \pm 7.9$ & $10.9 \pm 6.7$ & $10.4 \pm 6.3$ & 0.44 \\
K.I. & $13.8 \pm 10.7$ & $14.3 \pm 9.9$ & $11.5 \pm 9.2$ & 0.23 \\
\hline
\end{tabular}

MT, Menopausal Transition; ePM, early Post Menopause; PM, Post Menopause; ESS, Epworth Sleepiness Scale; PSQI, Pittsburgh Sleep Quality Index; BDI, Beck depression inventory; KI, Kupperman Index.

\section{Conclusions}

Compared to the most recent Literature, our data underline and confirm the relevance of sleep disorders in menopausal and perimenopausal women, even if no difference seems to emerge through the three stages of menopausal process. However, the data should be verified in population prevalence studies. We stress the importance of considering RLS and OSAS among other sleep disorders. 
These diagnoses should be confirmed by instrumental sleep studies. Given the different available therapeutic options for sleep disorders, (we suggest that) only a structured approach in selected, screened patients, could reach an effective treatment.

\section{Ethical Approval}

All procedures performed in studies involving human participants were in accordance with the ethical standards of the institutional and/or national research committee and with the 1964 Helsinki declaration and its later amendments or comparable ethical standards.

"Informed consent was obtained from all individual participants included in the study."

\section{Conflicts of Interest}

The authors declare that they have no conflict of interest.

\section{References}

[1] Cappuccio, F.P., Cooper, D., D’Elia, L., et al. (2011) Sleep Duration Predicts Cardiovascular Outcomes: A Systematic Review and Meta-Analysis of Prospective Studies. European Heart Journal, 32, 1484-1492. https://doi.org/10.1093/eurheartj/ehr007

[2] Ohayon, M.M., Carskadon, M.A., Guilleminault, C., et al. (2004) Meta-Analysis of Quantitative Sleep Parameters from Childhood to Old Age in Healthy Individuals: Developing Normative Sleep Values across the Human Lifespan. Sleep, 27, 1255-1273. https://doi.org/10.1093/sleep/27.7.1255

[3] Harlow, S.D., Gass, M., Hall, J.E., et al. (2012) Executive Summary of the Stages of Reproductive Aging Workshop +10: Addressing the Unfinished Agenda of Staging Reproductive Aging. Menopause, 19, 387-395. https://doi.org/10.1097/gme.0b013e31824d8f40

[4] Lindberg, E., Janson, C., Gislason, T., et al. (1997) Sleep Disturbances in a Young Adult Population: Can Gender Differences Be Explained by Differences in Psychological Status. Sleep, 20, 381-387. https://doi.org/10.1093/sleep/20.6.381

[5] Joffe, H., Massler, A. and Sharkey, K.M. (2010) Evaluation and Management of Sleep Disturbance during the Menopause Transition. Seminars in Reproductive Medicine, 28, 404-421. https://doi.org/10.1055/s-0030-1262900

[6] Woods, N.F. and Mitchell, E.S. (2010) Sleep Symptoms during the Menopausal Transition and Early Postmenopause: Observations from the Seattle Midlife Women's Health Study. Sleep, 33, 539-549. https://doi.org/10.1093/sleep/33.4.539

[7] Shin, C., Lee, S., Lee, T., et al. (2005) Prevalence of Insomnia and Its Relationship to Menopausal Status in Middle-Aged Korean Women. Psychiatry and Clinical Neurosciences, 59, 395-402. https://doi.org/10.1111/j.1440-1819.2005.01391.x

[8] Cheng, M.H., Hsu, C.Y., Wang, S.J., et al. (2008) The Relationship of Self-Reported Sleep Disturbance, Mood, and Menopause in a Community Study. Menopause, 15, 958-962. https://doi.org/10.1097/gme.0b013e318160dafa

[9] Hachul, H., Bittencourt, L.R., Soares, J.M., et al. (2009) Sleep in Post-Menopausal Women: Differences between Early and Late Post-Menopause. European Journal of 
Obstetrics and Gynecology and Reproductive Biology, 145, 81-84.

https://doi.org/10.1016/j.ejogrb.2009.03.019

[10] Freedman, R.R. and Roehrs, T.A. (2004) Lack of Sleep Disturbance from Menopausal Hot Flashes. Fertility and Sterility, 82, 138-144.

https://doi.org/10.1016/j.fertnstert.2003.12.029

[11] Xu, M., Bélanger, L., Ivers, H., et al. (2011) Comparison of Subjective and Objective Sleep Quality in Menopausal and Non-Menopausal Women with Insomnia. Sleep Medicine, 12, 65-69. https://doi.org/10.1016/j.sleep.2010.09.003

[12] Kalleinen, N., Polo-Kantola, P., Himanen, S.L., et al. (2008) Sleep and the Menopause-Do Postmenopausal Women Experience Worse Sleep than Premenopausal Women? Menopause International, 14, 97-104.

https://doi.org/10.1258/mi.2008.008013

[13] Lampio, L., Saaresranta, T., Engblom, J., et al. (2016) Predictors of Sleep Disturbance in Menopausal Transition. Maturitas, 94, 137-142. https://doi.org/10.1016/j.maturitas.2016.10.004

[14] Woodward, S. and Freedman, R.R. (1994) The Thermoregulatory Effects of Menopausal Hot Flashes on Sleep. Sleep, 17, 497-501.

https://doi.org/10.1093/sleep/17.6.497

[15] Toffol, E., Kalleinen, N., Urrila, A.S., et al. (2014) The Relationship between Mood and Sleep in Different Female Reproductive States. BMC Psychiatry, 14, 177. https://doi.org/10.1186/1471-244X-14-177

[16] Freedman, R.R., Norton, D., Woodward, S., et al. (1995) Core Body Temperature and Circadian Rhythm of Hot Flashes in Menopausal Women. The Journal of Clinical Endocrinology \& Metabolism, 80, 2354-2358. https://doi.org/10.1210/jcem.80.8.7629229

[17] Freedman, R.R and Krell, W. (1999) Reduced Thermoregulatory Null Zone in Postmenopausal Women with Hot Flashes. American Journal of Obstetrics \& Gynecology, 181, 66-70. https://doi.org/10.1016/S0002-9378(99)70437-0

[18] Freeman, E.W. and Sherif, K. (2007) Prevalence of Hot Flushes and Night Sweats around the World: A Systematic Review. Climacteric, 10, 197-214. https://doi.org/10.1080/13697130601181486

[19] Gartoulla, P., Islam, M.R., Bell, R.J. and Davis, S.R. (2014) Prevalence of Menopausal Symptoms in Australian Women at Midlife: A Systematic Review. Climacteric, 17, 529-539. https://doi.org/10.3109/13697137.2013.865721

[20] Nelson, H., Haney, E., Humphreyet, L., et al. (2005) Management of Menopause-Related Symptoms. Evidence Report/Technology Assessment 120, Agency for Healthcare Research and Quality, Rockville, MD.

[21] Koster, A., Eplov, L.F., Garde, K., et al. (2002) Anticipations and Experiences of menopause in a Danish Female General Population Cohort Born in 1936. Archives of Women's Mental Health, 5, 9-13. https://doi.org/10.1007/s007370200017

[22] Joffe, H., Crawford, S., Economou, N., et al. (2013) A Gonadotropin-Releasing Hormone Agonist Model Demonstrates that Nocturnal Hot Flashes Interrupt Objective Sleep. Sleep, 36, 1977-1985. https://doi.org/10.5665/sleep.3244

[23] Ensrud, K.E., Stone, K.L., Blackwell, T.L., et al. (2009) Frequency and Severity of Hot Flashes and Sleep Disturbance in Postmenopausal Women with Hot Flashes. Menopause, 16, 286-292. https://doi.org/10.1097/gme.0b013e31818c0485

[24] Joffe, H., White, D.P., Crawford, S.L., et al. (2013) Adverse Effects of Induced Hot Flashes on Objectively Recorded and Subjectively Reported Sleep: Results of a Go- 
nadotropin-Releasing Hormone Agonist Experimental Protocol. Menopause, 20, 905-914. https://doi.org/10.1097/GME.0b013e31828292d1

[25] Freedman, R.R. and Roehrs, T.A. (2006) Effects of REM Sleep and Ambient Temperature on Hot Flash-Induced Sleep Disturbance. Menopause, 13, 576-583. https://doi.org/10.1097/01.gme.0000227398.53192.bc

[26] de Zambotti, M., Colrain, I.M., Javitz, H.S. and Baker, F.C. (2014) Magnitude of the Impact of Hot Flashes on Sleep in Perimenopausal Women. Fertility and Sterility, 102, 1708-1715. https://doi.org/10.1016/j.fertnstert.2014.08.016

[27] Lentz, M.J., Landis, C.A., Rothermel, J. and Shaver, J.L. (1999) Effects of Selective Slow Wave Sleep Disruption on Musculoskeletal Pain and Fatigue in Middle Aged Women. The Journal of Rheumatology, 26, 1586-1592.

[28] Ohayon, M.M. (2006) Severe Hot Flashes are Associated with Chronic Insomnia. Archives of Internal Medicine, 166, 1262-1268. https://doi.org/10.1001/archinte.166.12.1262

[29] Steinberg, E.M., Rubinow, D.R., Bartko, J.J., et al. (2008) A Cross-Sectional Evaluation of Perimenopausal Depression. The Journal of Clinical Psychiatry, 69, 973-980. https://doi.org/10.4088/JCP.v69n0614

[30] Bromberger, J.T. and Kravitz, H.M. (2011) Mood and Menopause: Findings from the Study of Women's Health across the Nation (SWAN) over 10 Years. Obstetrics and Gynecology Clinics of North America, 38, 609-625. https://doi.org/10.1016/j.ogc.2011.05.011

[31] Bromberger, J.T., Matthews, K.A., Schott, L.L., et al. (2007) Depressive Symptoms during the Menopausal Transition: The Study of Women's Health across the Nation (SWAN). Journal of Affective Disorders, 103, 267-272. https://doi.org/10.1016/j.jad.2007.01.034

[32] Soares, C.N. (2014) Mood Disorders in Midlife Women: Understanding the Critical Window and its Clinical Implications. Menopause, 21, 198-206. https://doi.org/10.1097/GME.0000000000000193

[33] Sivertsen, B., Salo, P., Mykletun, A., et al. (2012) The Bidirectional Association between Depression and Insomnia: the HUNT Study. Psychosomatic Medicine, 7, 758-765. https://doi.org/10.1097/PSY.0b013e3182648619

[34] Riemann, D. (2007) Insomnia and Comorbid Psychiatric Disorders. Sleep Medicine, 4, 15-20. https://doi.org/10.1016/S1389-9457(08)70004-2

[35] Moe, K.E. (2004) Hot Flashes and Sleep in Women. Sleep Medicine Reviews, 8, 487-497. https://doi.org/10.1016/j.smrv.2004.07.005

[36] Joffe, H., Soares, C.N., Thurston, R.C., et al. (2009) Depression Is Associated with Worse Objectively and Subjectively Measured Sleep, but Not More Frequent Awakenings, in Women with Vasomotor Symptoms. Menopause, 16, 671-679. https://doi.org/10.1097/gme.0b013e3181957377

[37] Terashima, K., Mikami, A., Tachibana, N., Kumano-Go, T., et al. (2004) Sleep Characteristics of Menopausal Insomnia: A Polysomnographic Study. Psychiatry and Clinical Neurosciences, 58, 179-185. https://doi.org/10.1111/j.1440-1819.2003.01214.x

[38] Allen, R.P., Walters, A.S., Montplaisir, J., et al. (2005) Restless Legs Syndrome Prevalence and Impact: REST General Population Study. Archives of Internal Medicine, 165, 1286-1292. https://doi.org/10.1001/archinte.165.11.1286

[39] Earley, C.J., Connor, J.R., Beard, J.L., et al. (2000) Abnormalities in CSF Concentrations of Ferritin and Transferrin in Restless Legs Syndrome. Neurology, 54, 
1698-1700. https://doi.org/10.1212/WNL.54.8.1698

[40] Gigli, G.L., Adorati, M., Dolso, P., et al. (2004) Restless Legs Syndrome in End-Stage Renal Disease. Sleep Medicine, 5, 309-315. https://doi.org/10.1016/j.sleep.2004.01.014

[41] Merlino, G., Fratticci, L., Valente, M., et al. (2007) Association of Restless Legs Syndrome in Type 2 Diabetes: A Case-Control Study. Sleep, 30, 866-871. https://doi.org/10.1093/sleep/30.7.866

[42] Kenzedrsa,T., Kamra, M., Murray, B.J., et al. (2017) Incident Cardiovascular Events and Death in Individuals With Restless Legs Syndrome or Periodic Limb Movements in Sleep: A Systematic Review. Sleep, 40, zsx013. https://doi.org/10.1093/sleep/zsx013

[43] Katsanos, A.H., Kosmidou, M., Konitsiotis, S., et al. (2017) Restless Legs Syndrome and Cerebrovascular/Cardiovascular Events: Systematic Review and Meta-Analysis. Acta Neurologica Scandinavica, 137, 142-148. https://doi.org/10.1111/ane.12848

[44] Allen, R.P. (2015) Restless Leg Syndrome/Willis-Ekbom Disease Pathophysiology. Sleep Medicine Clinics, 10, 207-214. https://doi.org/10.1016/j.jsmc.2015.05.022

[45] Khan, F.H., Ahlberg, C.D., Chow, C.A., et al. (2017) Iron, Dopamine, Genetics, and Hormones in the Pathophysiology of Restless Legs Syndrome. Journal of Neurology, 264, 1634-1641. https://doi.org/10.1007/s00415-017-8431-1

[46] Connor, J.R., Ponnuru, P., Wang, X.S., et al. (2011) Profile of Altered Brain Iron Acquisition in Restless Legs Syndrome. Brain, 134, 959-968.

https://doi.org/10.1093/brain/awr012

[47] Wesstrom J, Nilsson S, Sundstrom-Poromaa I, et al. (2008) Restless Legs Syndrome among Women: Prevalence, Co-Morbidity and Possible Relationship to Menopause. Climacteric, 11, 422-428. https://doi.org/10.1080/13697130802359683

[48] Dzaja, A., Wehrle, R., Lancel, M. and Pollmächer, T. (2009) Elevated Estradiol Plasma Levels in Women with Restless Legs during Pregnancy. Sleep, 32, 169-174. https://doi.org/10.1093/sleep/32.2.169

[49] Ghorayeb, I., Bioulac, B., Scribans, C., et al. (2008) Perceived Severity of Restless Legs Syndrome across the Female Life Cycle. Sleep Medicine, 9, 799-802. https://doi.org/10.1016/j.sleep.2007.07.018

[50] Fabbrini, M., AricÃ, I., Tramonti, F., et al. (2015) Sleep Disorders in Menopause: Results from an Italian Multicentric Study. Archives Italiennes de Biologie, 153, 204-213.

[51] Nichols, D.A., Allen, R.P., Grauke, J.H., et al. (2003) Restless Legs Syndrome Symptoms in Primary Care: A Prevalence Study. Archives of Internal Medicine, 163, 2323-2329. https://doi.org/10.1001/archinte.163.19.2323

[52] Marin, J.M., Carrizo, S.J., Vicente, E., et al. (2005) Long-Term Cardiovascular Outcomes in Men with Obstructive Sleep Apnoea-Hypopnoea with or without Treatment with Continuous Positive Airway Pressure: An Observational Study. The Lancet, 365, 1046-1053.

[53] Hall, M.H., Kline, C.E. and Nowakowski, S. (2015) Insomnia and Sleep Apnea in Midlife Women: Prevalence and Consequences to Health and Functioning. Prime Reports, 7, 63. https://doi.org/10.12703/P7-63

[54] Orth, M., Kotterba, S., Rasche, K., et al. (2007) Sleep Apnoea in Women? The Forgotten Gender. Pneumologie, 61, 725-729. https://doi.org/10.1055/s-2007-980128

[55] Jehan, S., Masters-Isarilov, A., Salifu, I., et al. (2015) Sleep Disorders in Postmeno- 
pausal Women. Journal of Sleep Disorders and Therapy, 4, Article ID: 1000212.

[56] Koo, S.K., Ahn, G.Y., Cho, J.W., et al. (2017) Obstructive Sleep Apnea in Postmenopausal Women: A Comparative Study Using Drug Induced sleep Endoscopy. Brazilian Journal of Otorhinolaryngology, 83, 285-291. https://doi.org/10.1016/j.bjorl.2016.03.011

[57] Liu, Y.-H., Huang, Y. and Shao, X. (2009) Effects of Estrogen on Genioglossal Muscle Contractile Properties and Fiber-Type Distribution in Chronic Intermittent Hypoxia Rats. European Journal of Oral Sciences, 117, 685-690. https://doi.org/10.1111/j.1600-0722.2009.00681.x

[58] Preston, M.E., Jensen, D., Janssen, I. and Fisher, J.T. (2009) Effect of Menopause on the Chemical Control of Breathing and Its Relationship with Acid-Base Status. American Journal of Physiology-Regulatory, Integrative and Comparative Physiology, 296, R722-R727. https://doi.org/10.1152/ajpregu.90865.2008

[59] Bixler, E.O., Vgontzas, A.N, Lin, H.-M., et al. (2001) Prevalence of Sleep-Disordered Breathing in Women: Effects of Gender. American Journal of Respiratory and Critical Care Medicine, 163, 608-613. https://doi.org/10.1164/ajrccm.163.3.9911064

[60] Shahar, E., Redline, S., Young, T., et al. (2003) Hormone Replacement Therapy and Sleep-Disordered Breathing. American Journal of Respiratory and Critical Care Medicine, 167, 1186-1192. https://doi.org/10.1164/rccm.200210-1238OC

[61] Polo-Kantola, P. (2008) Dealing with Menopausal Sleep Disturbances. Sleep Medicine Clinics, 3, 121-131. https://doi.org/10.1016/j.jsmc.2007.10.006

[62] Manber, R. and Armitage, R. (1999) Sex, Steroids and Sleep: A Review. Sleep, 22, 540-555.

[63] Friess, E., Tagaya, H., Trachsel, L., Holsboer, F. and Rupprecht, R. (1997) Progesterone-Induced Changes in Sleep in Male Subjects. American Journal of Physiology-Endocrinology and Metabolism, 272, E885-E891. https://doi.org/10.1152/ajpendo.1997.272.5.E885

[64] Savolainen-Peltonen, H., Hautamäki, H., Tuomikoski, P., et al. (2014) Health-Related Quality of Life in Women with or without Hot Flashes: A Randomized Placebo-Controlled Trial with Hormone Therapy. Menopause, 21, 732-739. https://doi.org/10.1097/GME.0000000000000120

[65] Welton, A.J., Vickers, M.R., Kim, J., et al. (2008) Health Related Quality of Life after Combined Hormone Replacement Therapy: Randomised Controlled Trial. BMJ, 337, a1190. https://doi.org/10.1136/bmj.a1190

[66] Hays, J., Ockene, J.K., Brunner, R.L., et al. (2003) Women's Health Initiative Investigators. Effects of Estrogen plus Progestin on Health-Related Quality of Life. The New England Journal of Medicine, 348, 1839-1854. https://doi.org/10.1056/NEJMoa030311

[67] Nikolaus, C., Netzer, M.D., Riccardo, A., et al. (1999) Using the Berlin Questionnaire To Identify Patients at Risk for the Sleep Apnea Syndrome. Annals of Internal Medicine, 131, 485-491. https://doi.org/10.7326/0003-4819-131-7-199910050-00002

[68] Walters, A.S., LeBrocq, C., Dhar, A., et al. (2003) Validation of the International Restless Legs Syndrome Study Group Rating Scale for Restless Legs Syndrome. Sleep Medicine, 4, 121-132. https://doi.org/10.1016/S1389-9457(02)00258-7

[69] Beck, A.T., Ward, C., Mendelson, M., et al. (1961) An Inventory for Measuring Depression. Archives of General Psychiatry, 4, 561-571. https://doi.org/10.1001/archpsyc.1961.01710120031004

[70] Johns, M.V. (1991) A New Method for Measuring Daytime Sleepiness: The Epworth 
Sleepiness Scale. Sleep, 14, 540-545. https://doi.org/10.1093/sleep/14.6.540

[71] Buysse, Daniel J.; Reynolds, et al. (1989) The Pittsburgh Sleep Quality Index: A New Instrument for Psychiatric Practice and Research. Psychiatry Research, 28, 193-213. https://doi.org/10.1016/0165-1781(89)90047-4

[72] Delaplaine, R.W., Bottomy, J.R. and Blatt, M. (1952) Effective Control of the Surgical Menopause by Estradiol Pellet Implantationat the Time of Surgery. Surgery, Gynecology \& Obstetrics, 94, 323-333. 